\title{
Non Compaction Cardiomyopathy Masquerading as Asthma: A Case Report
}

\author{
Bodar $\mathrm{VH}^{1, *}$, Upadhyay $\mathrm{A}^{1}$, Singh $\mathrm{S}^{1}$, Ullah $\mathrm{T}^{1}$, Colasacco $\mathrm{JA}^{2}$, Pinsker $\mathbf{R}^{1}$ \\ ${ }^{1}$ Department of Internal Medicine, Jamaica Hospital Medical Center, Jamaica, NY 11418, USA \\ ${ }^{2}$ Department of Cardiology, Jamaica Hospital Medical Center, Jamaica, NY 11418, USA \\ *Corresponding author: v.hbodar@yahoo.com
}

\begin{abstract}
Left ventricular non-compaction (LVNC) is a rare form of cardiomyopathy, which leads to progressive heart failure, arrhythmias, and thromboembolic events. Due to variable clinical presentations, it is often misdiagnosed as another cardiomyopathy or asthma. Here we report a case of 50 year-old-male who had multiple emergency room visits for shortness of breath (SOB) which were treated acutely with bronchodilators for presumptive asthma exacerbations. Subsequently, a 2D, color flow transthoracic echocardiogram was performed, which revealed the presence of dilated cardiomyopathy, and a low LV ejection fraction. In addition, left ventricular trabeculation was greater than that anticipated, with prominent inter trabecular recesses, supporting the diagnosis of LVNC. A family history of early onset heart failure was present. This case is presented to help physicians consider non-compaction cardiomyopathy as an etiology in patients who present with SOB and low ejection fraction (EF).
\end{abstract}

Keywords: cardiomyopathy, non-compaction, dyspnea, $\mathrm{SOB}$

Cite This Article: Bodar VH, Upadhyay A, Singh S, Ullah T, Colasacco JA, and Pinsker R, "Non Compaction Cardiomyopathy Masquerading as Asthma: A Case Report." American Journal of Medical Case Reports, vol. 5, no. 10 (2017): 256-258. doi: 10.12691/ajmcr-5-10-1.

\section{Introduction}

Non-compaction of the left ventricle is a congenital abnormality, occurring between 5 to 8 weeks of life, in which the myocardium fails to transform into compact. As a result the cardiac muscle takes a spongiform appearance with hypertrabeculation and deep recesses in the ventricular wall [1]. Left untreated, this defect in endomyocardial morphogenesis can result in a dilated cardiomyopathy \& severe systolic dysfunction [2]. Several genetic mutations have been identified including defects in the genes coding for $\alpha$-dystrobrevin, LIM domain binding protein 3, tropomyosin, tafazzin, , $\alpha$-cardiac actin etc. $[3,4]$. Due to recent advance in diagnostic imaging, the incidence has increased with current incidence of 3-4 \% in heart failure patients [5]. Non-compaction cardiomyopathy is usually diagnosed at a young age; however a few cases have been reported in an older age group [3]. The clinical presentation varies from asymptomatic to arrhythmia, heart failure, and systemic embolism. Here we present a case of a middle-aged African-American male presenting with dyspnea, treated as asthma exacerbation, but diagnosed with non-compaction cardiomyopathy and heart failure after echocardiographic evaluation.

\section{Case Presentation}

A 50-year-old African-American male with past medical history of asthma presented with shortness of breath (SOB) for 4 weeks. He reported progressive dyspnea for a few days prior to admission, especially walking 20 steps, climbing stairs, and at night. Bilateral lower extremity edema was present, but he denied any chest pain, palpitation, dizziness, wheezing, or cough. There was no history of hypertension, diabetes, coronary artery disease, recent febrile illness, or illicit drug use. The patient had similar episodes in the past, and was treated for asthma with albuterol with subsequent improvement. During the current episode, the patient attempted to use albuterol with little improvement of his symptoms. The patient was a non-smoker, and his family history was notable for a twin brother who recently had been diagnosed with congestive heart failure (CHF).

On examination, the patient was afebrile, normotensive, tachycardic (HR $101 \mathrm{bpm}$ ), with respiratory rate of 18 breaths per minute, and $\mathrm{SpO} 2$ 98\%. Cardiac examination revealed gallop with no murmur or rub. Bibasilar crepitations were noticed on lung examination. No hepatomegaly or splenomegaly was noted. 1+ lower extremity pitting edema was present. Electrocardiography (ECG) showed left ventricular hypertrophy with T-wave inversions in inferolateral leads and biatrial enlargement. Chest X-ray revealed an enlarged cardiac silhouette, consistent with congestive changes. Significant labs includes; BNP -1030.0 (0-125.0 Pg/mL), troponin - 0.08 (0-0.033 ng/mL), creatinine - 1.6 (0.7-1.3 $\mathrm{mg} / \mathrm{dL})$, AST - 88 (17-59 U/L), and ALT - 100 (21-72 U/L). Urine toxicology was negative. Treatment was started on diuretics, $\beta$-blocker, aspirin, ACE inhibitor, and heparin drip due to elevated troponin and $\mathrm{T}$-wave inversion. 
Transthoracic echocardiography revealed a dilated left ventricle with EF of $10-15 \%$ and false tendon in the left ventricle with prominent trabeculations along the apical and lateral walls, with multiple intertrabecular recesses suggestive of left ventricular (LV) non-compaction (Figure 1, Figure 2A and Figure 2B). End systolic ratio of non-compacted to compacted layer was $\geq 2$. Left atrium was dilated and mitral and tricuspid valve showed mild to moderate regurgitation without any stenosis.

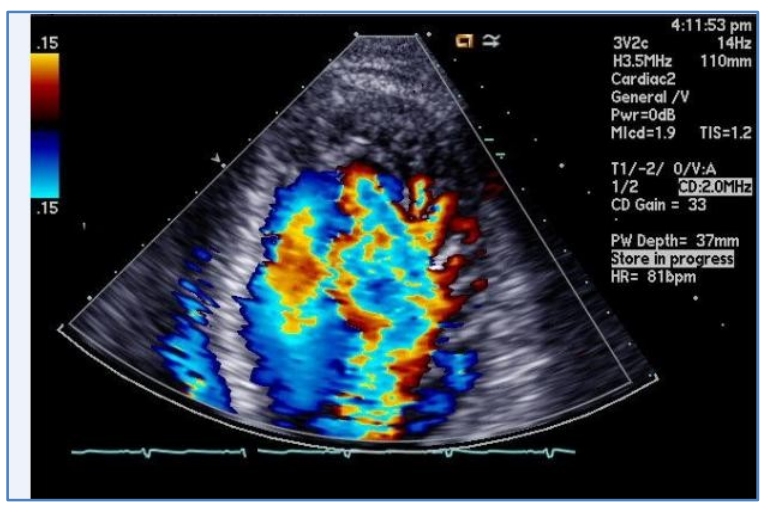

Figure 1. Evidence of direct blood flow from the ventricular cavity into deep intratrabecular recesses via color Doppler echocardiography

A
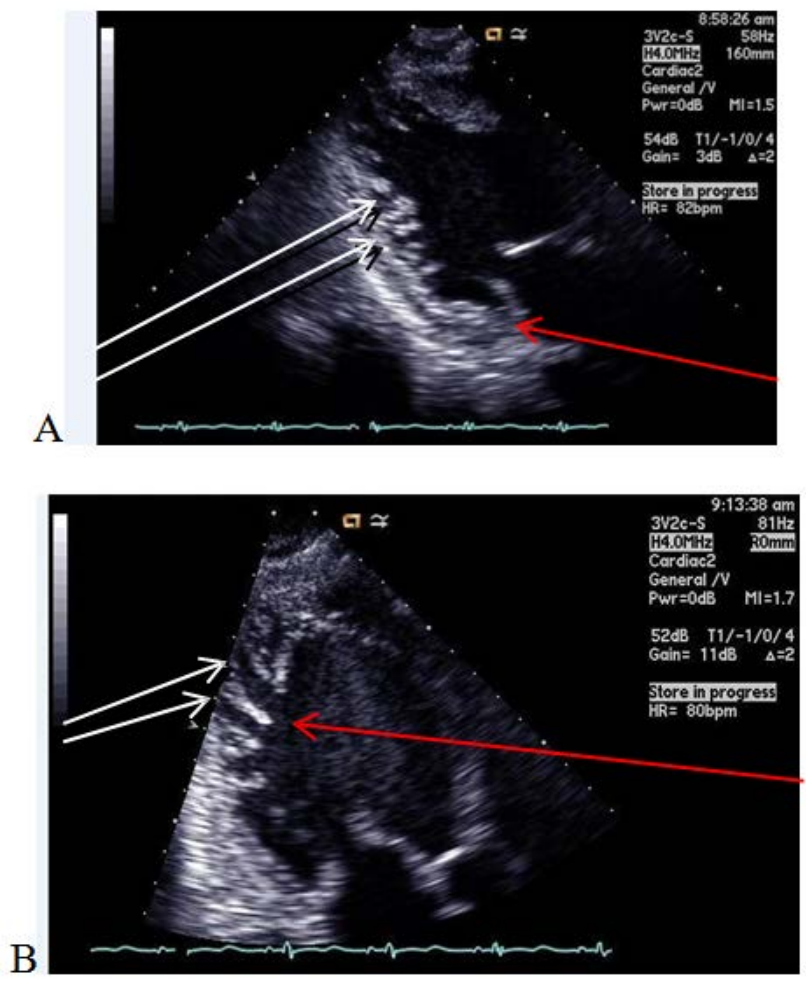

Figures 2A and B. Left ventricular long axis view showing prominent trabeculations (Red arrows) and deep recesses (White arrows) by transthoracic echocardiography. The ratio of thick non-compacted layer to thin compacted layer is $\geq 2$.

The patient was advised to have cardiac catheterization, but he refused because of the possible procedural risks. A nuclear stress test was performed, and was negative for ischemia. He was counseled regarding the importance of medication compliance, and was discharged with a diuretic, $\beta$-blocker, and ACE inhibitor. At his follow-up appointment, a repeat echocardiogram showed EF of $20 \%$ and automatic Implantable cardioveter defibrillator (AICD) was placed by electrophysiologist.

\section{Discussion}

LVNC is an uncommon genetic cardiomyopathy with an estimated prevalanvce of 0.01 to $0.05 \%$ in adults [2]. Because of its variable phenotypical and clinical presentation, it is often unrecognized and misdiagnosed as another cardiomyopathies or diseases [6,7]. The diagnosis typically requires genetic testing combined with various cardiac imaging modalities $[3,6]$. The echocardiogram is often suggestive, and key features of LVNC include: prominent $\mathrm{LV}$ trabeculum with deep intertrabecular recesses particularly in the apical and lateral walls; prominent color flow in the trabecular recesses; a double layer ventricular wall with an end systolic ratio of non compacted to compacted myocardium of $>2[6,8,9]$. These features help differentiate LVNC from hypertrophic cardiomyopathy (HCM) and dilated cardiomyopathy due to LVH. In addition, administration of IV contrast can increase the detection of trabeculae, trabecular recess and LV thrombi. Of note cardiac MRI offers better spatial resolution than echocardiogram and MRI based morphological features provide prognostic information with regard to recovery of LV systolic function and the incidence of tachyarrthymia [10]. The presence of late gadolinium enhancement on MRI associated with worse outcomes [10].

Clinically, the absence of ventricular myocardiac compaction is associated with CHF, arrhythmia, thromboembolism [11]. Prognosis depends on ratio of non compacted to compacted myocardium as well as the degree of the LV systolic dysfunction [11]. Current guidelines recommend standard therapy with combinations of B blockers, ACE/ ARBS, diuretics and aldosterone antagonists [12]. Anti coagulation is indicated in patients with a history of thromboembolism and may be considered in those with a dilated LV and LVEF $<40 \%$. The role of anticoagulation in preserved EF is controversial [13]. Since patients are at increased risk for sudden cardiac death (SCD), patients should be screened for the presence of ventricular arrthymias. Stanton et al [14] reported ventricular tachycardia in $27 \%$ of LVNC on Holter monitoring. An AICD is indicated in patients with sustained ventricular tachycardia or those who have survived cardiac arrest. In all other patients with reduced EF prophylactic AICD may be considered (ACC/ AHA, class II b heart failure, 2012 guidelines on device heart therapy) [15]. Radio frequency ablation may be a treatment option [16]. Genetic testing for LVNC should be considered in family members and appropriate relatives following the identification of a LVNC causative mutation in the index case [17].

\section{Conclusion}

In conclusion, because it is often overlooked or misdiagnosed, left ventricular non compaction should be considered in patients with a family history of CHF who present with dyspnea and are subsequently found to have 
a dilated cardiomyopathy. Proper evaluation along with screening among family members may be the key to decreasing the morbidity and mortality of this congenital cardiomyopathy.

\section{Conflict of Interest}

The authors declare no conflict of interest.

\section{References}

[1] Bhat T, Lafferty J, Teli S, Rjaili GA, Olkovsky Y, Costantino T. Isolated. Left Ventricular Noncompaction Cardiomyopathy diagnosed by Transesophageal Echocardiography. Clinical Medicine Insights Cardiology. 2011; 5: 23-27.

[2] Hussein A, Karimianpour A, Collier P, Krasuski RA. Isolated Noncompaction of the Left Ventricle in Adults. J Am Coll Cardiol. 2015 Aug 4; 66(5): 578-85.

[3] Steger CM.Left ventricular non-compaction. BMJ Case Rep. 2014 Jun 24; 2014.

[4] Vatta M, Mohapatra B, Jimenez S, Sanchez X, Faulkner G, Perles Z, Sinagra G, Lin JH, Vu TM, Zhou Q, Bowles KR, Di Lenarda A, Schimmenti L, Fox M, Chrisco MA, Murphy RT, McKenna W, Elliott P, Bowles NE, Chen J, Valle G, Towbin JA. Mutations in Cypher/ZASP in patients with dilated cardiomyopathy and lef ventricular non-compaction. J Am Coll Cardiol. 2003 Dec 3; 42(11): 2014-27.

[5] Kovacevic-Preradovic T, Jenni R, Oechslin EN, Noll G, Seifert B, Attenhofer Jost $\mathrm{CH}$. Isolated left ventricular noncompaction as a cause for heart failure and heart transplantation: a single center experience. Cardiology. 2009; 112(2): 158-64.

[6] Haland TF, Saberniak J, Leren IS, Edvardsen T, Haugaa KH.Echocardiographic comparison between left ventricular noncompaction and hypertrophic cardiomyopathy. International Journal of Cardiology.2017 Feb 1; 228: 900-905.

[7] Ikeda U., Minamisawa M., Koyama J. Isolated left ventricular non-compaction cardiomyopathy in adults. Journal of Cardiology. 2015, 65 2: 91-97.

[8] Jenni R, Oechslin E, Schneider J, Attenhofer Jost C, Kaufmann PA. Echocardiographic and pathoanatomical characteristics of isolated left ventricular non-compaction: a step towards classification as a distinct cardiomyopathy. Heart. 2001; 86(6): 666-71.

[9] Ross T. Murphy, Rajesh Thaman, Juan Gimeno Blanes, Deirdre Ward, Elias Sevdalis, Efi Papra, Anatoli Kiotsekolglou, Maria T. Tome, Denis Pellerin, William J. McKenna, Perry M. Elliott.
Natural history and familial characteristics of isolated left ventricular non-compaction. Eur Heart J. 2005; 26(2): 187-192.

[10] Ashrith G, Gupta D, Hanmer J, Weiss RM. Cardiovascular magnetic resonance characterization of left ventricular noncompaction provides independent prognostic information in patients with incident heart failure or suspected cardiomyopathy. Journal of Cardiovascular Magnetic Resonance. 2014; 16(1): 64.

[11] Goud A, Padmanabhan S. A rare form of cardiomyopathy: left ventricular non-compaction cardiomyopathy. Journal of Community Hospital Internal Medicine Perspectives. 2016; 6(1):10.3402/jchimp.v6.29888.

[12] Shemisa K, Li J, Tam M, Barcena J. Left ventricular noncompaction cardiomyopathy. Cardiovasc Diagn Ther. 2013 Sep; 3(3): 170-175.

[13] Stöllberger C, Finsterer J. Thrombi in left ventricular hypertrabeculation/noncompaction--review of the literature. Acta Cardiol. 2004 Jun; 59(3):341-4. Review.

[14] Stanton C., Bruce C., Connolly H., Brady P., Syed I., Hodge D., Asirvatham S., Friedman P. Isolated Left Ventricular Noncompaction Syndrome. American Journal of Cardiology. 2009; 104: 8: 1135-1138.

[15] Epstein AE, DiMarco JP, Ellenbogen KA, Estes NA 3rd, Freedman RA, Gettes LS, Gillinov AM, Gregoratos G, Hammill SC, Hayes DL, Hlatky MA, Newby LK, Page RL, Schoenfeld MH, Silka MJ, Stevenson LW, Sweeney MO, Smith SC Jr, Jacobs AK, Adams, CD, Anderson JL, Buller CE, Creager MA, Ettinger SM, Faxon DP, Halperin JL, Hiratzka LF, Hunt SA, Krumholz HM, Kushner FG, Lytle BW, Nishimura RA, Ornato JP, Page RL, Riegel B, Tarkington LG, Yancy CW; American College of Cardiology/American Heart Association Task Force on Practice Guidelines (Writing) Committee to Revise the ACC/AHA/NASPE 2002 Guideline Update for Implantation of Cardiac Pacemakers and Antiarrhythmia Devices).; American Association for Thoracic Surgery.; Society of Thoracic Surgeons. ACC/AHA/HRS 2008 Guidelines for Device-Based Therapy of Cardiac Rhythm Abnormalities: a report of the American College of Cardiology/American Heart Association Task Force on Practice Guidelines (Writing Committee to Revise the ACC/AHA/NASPE 2002 Guideline Update for Implantation of Cardiac Pacemakers and Antiarrhythmia Devices) developed in collaboration with the American Association for Thoracic Surgery and Society of Thoracic Surgeons. J Am Coll Cardiol. 2008 May 27; 51(21): e1-62. Erratum in: J Am Coll Cardiol. 2009 apr, 21; 53(16):1473. J Am Coll Cardiol. 2009 Jan 6; 53(1):147.

[16] Chinushi M, Iijima K, Furushima H, Izumi D, Sato A, Yagihara N, Hasegawa K, Watanabe H, Soejima K, Aizawa Y. Suppression of storms of ventricular tachycardia by epicardial ablation of isolated delayed potential in noncompaction, cardiomyopathy. Pacing Clin Electrophysiol. 2013 Apr; 36(4):e115-9.

[17] Ackerman, M.J., Priori, S.G., Willems, S. et al, HRS/EHRA Expert Consensus Statement on the State of Genetic Testing for the Channelopathies and Cardiomyopathies. Europace. 2011; 13:1077-1109. 